\title{
ENCARCERAMENTO EM MASSA E A FRAGILIDADE DA ATUAÇÃO PENAL BRASILEIRA FRENTE A UMA PERSPECTIVA DE DIREITO COMO INTEGRIDADE: UMA ANÁLISE DO CASO RAFAEL BRAGA
}

\author{
Mass incarceration and the fragility of Brazilian criminal action
}

Yago Guerra Lustosa de Jesus ${ }^{1}$

\begin{abstract}
RESUMO: Esse trabalho propõe-se a analisar a cultura do encarceramento em massa no Brasil, sob a luz da teoria de Direito como Integridade do pensador norte-americano Ronald Dworkin (tratada aqui como tipo ideal), e sobre plano de fundo do emblemático caso do jovem catador latinhas Rafael Braga Vieira, condenado por tráfico de drogas, somente com base nos depoimentos dos policiais por ele acusados de tê-lo incriminado (Processo $\mathrm{N}^{\circ}$ 000856671.2016.8.19.0001). Para isso, fazendo uso de pesquisas bibliográficas, principalmente no âmbito da obra "Império do Direito", e documentais, como diversos relatórios sobre segurança pública e trabalhos acadêmicos derivados da teoria dworkianas. Outrossim, tratando os temas transversais que sustentam ou derivam das distorções legais brasileiras como: racismo, guerra às drogas, atuação policial e insalubridade carcerária.
\end{abstract}

Palavras-chave: Encarceramento; Rafael Braga; Dworkin; Justiça; Equidade.

\begin{abstract}
This paper proposes to analyze the culture of mass incarceration in Brazil, in light of the theory of Right as Integrity of the American thinker Ronald Dworkin (treated here as the ideal type), and on the background of the emblematic case of the young A canonist Rafael Braga Vieira, convicted of drug trafficking, based only on the testimony of the police officers accused of having charged him (Case No. 0008566-71.2016.8.19.0001). For this, making use of bibliographical research, mainly in the scope of the work "Empire of the Right", and documentary research, as diverse reports on public security and academic works derived from Dworkian theory. Also, dealing with the cross-cutting themes that sustain or derive from Brazilian legal distortions such as racism, drug war, police action and prison unhealthiness.
\end{abstract}

Key-words: Incarceration; Rafael Braga; Dworkin; Justice; Equity.

\section{INTRODUÇÃO}

Muito se tem discutido sobre justiça no Brasil, contudo, na eterna disputa entre o revanchismo punitivo, incutido no imaginário popular pelo sensacionalismo midiático, e o projeto de construção de uma sociedade inclusiva e ressocializadora, tem-se tido sistematicamente a vitória do primeiro.

O Brasil conta hoje com 654.372 presos $^{2}$, segundo dados do Concelho Nacional de Justiça, o que rende ao país o quarto lugar dentre as nações que mais encarceram seus cidadãos

\footnotetext{
${ }^{1}$ Graduando em Direito na Universidade Federal do Piauí. Email: yagolguerra@gmail.com
} 
no mundo. Essa situação por si só já é alarmante, especialmente quando relacionada com a desumanidade dos estabelecimentos prisionais, amplamente denunciados por organismos que vão das Nações Unidas a autoridades religiosas como o Papa Francisco. Contudo, evolui-se para o descalabro notar que, deste montante humano, $221.054^{3}$ são apenas presos provisórios. Ou seja, submetem-se as centenas de milhares de cidadãos e cidadãs desse país a uma vasta gama de violações de direitos humanos, sem ao menos a garantia de que as infrações que lhes são imputadas são verdadeiras.

Ainda assim, nem os condenados estão em situação menos periclitante. Além das condições de encarceramento anteriormente citadas, em muitos casos, pesa a dúvida quanto ao mérito de suas condenações. Segundo o Núcleo de Estudos da Violência (NEV) da USP, em $74 \%$ dos inquéritos por tráfico de drogas (principal causa de prisão no Brasil atualmente), a imputação decorre exclusivamente do depoimento do agente policial que efetuou a prisão. Havendo no meio jurídico uma forte aceitação dessa precariedade processual como fundamentação fática para o uso do aparelho repressor do Estado.

Nessa situação, inclui-se o jovem Rafael Braga, cujo caso repercutiu nos meios de comunicação ao ser condenado à draconiana pena de onze anos e três meses de prisão, com base exclusivamente no depoimento da autoridade policial, acusada pelo réu de ter-lhe incriminado deliberadamente, inclusive com testemunha ocular. Ronald Dworkin em seu conhecido livro "Império do Direito" (1999) defende a capacidade do magistrado para chegar à resposta correta diante do problema concreto. Todavia, ao defender sua proposta de Direito como integridade, ressalta a necessidade de submete-se as decisões ao crivo dos filtros de justiça, equidade e devido processo legal, o que aparentemente não ocorreu.

Braga teve a vida destroçada e está, nesse momento, sob as insalubres condições dos presídios brasileiros. Contudo, vê-se que pela perspectiva da moral pública, e de boa parte do próprio meio jurídico, há dúvida, para não dizer a descrença, na resistência dessa sentença frente aos crivos acima mencionados, bem como quanto ao respeito à garantia constitucional da presunção de inocência. Princípio esse que o Brasil ignora, junto com a generalidade e a abstratividade da lei esperadas de um sistema jurídico moderno, para aplicar sob uma lógica colonial do milênio passado, princípios e garantias somente a brancos, com boas condições financeiras, e provenientes de bairros tradicionais. O que, infelizmente, não configura o perfil

\footnotetext{
2 Dado disponível no documento "Reunião Especial de Jurisdição: Concelho Nacional de Justiça 2017.

${ }^{3}$ Dado disponível no documento "Reunião Especial de Jurisdição: Concelho Nacional de Justiça 2017.
} 
socioeconômico do catador de latinhas Rafael Braga Vieira, ou da esmagadora maioria dos internos do falido sistema carcerário nacional.

Nessa conjuntura, esse artigo propõe-se a analisar, a cultura do encarceramento em massa no Brasil, sob a luz dos conceitos introdutórios da teoria do pensador norte-americano Ronald Dworkin, de Direito como integridade, e o plano de fundo do emblemático caso do jovem catador latinhas Rafael Braga Vieira, condenado por tráfico de drogas, somente com base nos depoimentos dos policiais por ele acusados de tê-lo incriminado. Ainda nesse sentido, sendo tratados brevemente temas intimamente ligados ao problema em questão como: racismo, guerra às drogas, atuação policial e insalubridade carcerária.

Por conseguinte, propõe-se o questionamento: o Brasil possui de fato um sistema legal justo e equitativo como faz crer, a Constituição Federal de 1988? O presente artigo busca revelar que não, mostrando com o caso Rafael Braga que as garantias individuais e processuais precursoras desse anseio, são válidas somente para alguns, contrariando a generalidade do Estado de Direito.

Para isso, fazendo uso de pesquisas bibliográficas, com destaque para o livro "Império do Direito" (DWORKIN, 1999), e documentais, classificáveis em dois grandes grupos: artigos e demais produções científicas fulcradas na teoria dworkiana ${ }^{4}$, como o texto de Venturini (2011) "Dignidade e os direitos humanos: a concepção filosófica de Ronald Dworkin", e a respeito do sistema penal e penitenciário nacional como: "Sistema penitenciário brasileiro: (Dis)Função (Des)Socializadora" (PIVA; RAMIDOFF, 2015) além de diversos relatórios a respeito da segura pública brasileira como o INFOPEN-2014 e o ICJBrasil - 1º Semestre de 2016, produzidos e/ou divulgados pelo Departamento Penitenciário Nacional e a Fundação Getúlio Vargas, respectivamente.

\section{O RACISMO INSTITUCIONAL E O ROMPIMENTO COM A IDEIA DE ROMANCE EM CADEIA}

Dworkin propõe um sistema jurídico moralmente coerente tanto internamente, como com a moral da sociedade que pretende regular. O jurisfilósofo parte da ideia de que são necessários três filtros para a produção da resposta correta: justiça, equidade e devido processo legal adjetivo. Para tanto, faz uso de um tipo ideal por ele denominado de juiz Hércules (isso no âmbito judicial, na qual o presente trabalho tem enfoque), que, na presença de um caso difícil,

\footnotetext{
${ }^{4}$ A teoria de Dworkin será trabalhada em grande parte desse artigo como algo próximo a um tipo ideal, no sentido de um dever ser com o qual a realidade será contrastada para um melhor entendimento das deformidades existentes no modelo real.
} 
analisa-o de forma cuidadosa e metódica, considerando todas as variáveis e possíveis interpretações. Desse processo, inevitavelmente, resultaria a única resposta correta.

Ainda é relevante lembrar que, como tipo ideal, Dworkin não crê que algum humano de fato chegará a esse nível de perfeição, mas pretende que os magistrados tenham empenho em chegar o mais próximo possível disso, e nesse desenrolar coerente, formem um "romance em cadeia" com a tradição jurisprudencial dessa comunidade. Nesse ponto, argumentando em favor de sua construção como uma única obra, fruto da vontade da comunidade personificada, como mostram as palavras do autor:

Em tal projeto, um grupo de romancistas escreve um romance em série; cada romancista da cadeia interpreta os capítulos que recebeu para escrever um novo capítulo, que é então acrescentado ao que recebe o romancista seguinte, e assim por diante. Cada um deve escrever seu capítulo de modo a criar da melhor maneira possível, o romance em elaboração, e a complexidade dessa tarefa reproduz a complexidade de decidir um caso difícil de Direito como integridade. (DWORKIN, 1999, p. 276)

Todavia, essa ideia de unidade parece não existir no Brasil. Aqui, segundo dados do Levantamento Nacional de Informações Penitenciárias INFOPEN - Julho de 2014, dois a cada três indivíduos privados de liberdade, são pretos ou pardos. Esses dados mostram uma clara propensão do Poder Judiciário ao punitivismo baseado no encarceramento quando se trata de afro-brasileiros. Uma vez que, mesmo a população em geral sendo ligeiramente composta mais por negros ou pardos (51\%), o descompasso com os indivíduos privados de liberdade é acentuado, sendo eles a grande maioria dos presos (67\%).

Diante disso, torna-se no mínimo extremamente difícil encarar o sistema legal sobe uma perspectiva de unidade, sendo que, metade da população tem 1,5 mais chances de ser encarceram que o restante da população nacional. Rompe-se aqui não só o romance em cadeia, mas com preceitos básicos de um Estado Democrático de Direito, como a equidade e a isonomia (abertamente defendida por Dworkin como meio de chegar à resposta correta) bem como com princípios constitucionalmente previstos em sua decorrência como evidência o Artigo $5^{\circ} \mathrm{da}$ Constituição Federal (1988):

Art. $5^{\circ}$ Todos são iguais perante a lei, sem distinção de qualquer natureza, garantindo-se aos brasileiros e aos estrangeiros residentes no País a inviolabilidade do direito à vida, à liberdade, à igualdade, à segurança e à propriedade, nos termos seguintes: 
Com destaque para o inciso III:

III - ninguém será submetido a tortura nem a tratamento desumano ou degradante;

E para o inciso XLII que dispõe o de forma condenatória sobre o que parece ser a prática do próprio Estado brasileiro:

XLII - a prática do racismo constitui crime inafiançável e imprescritível sujeito à pena de reclusão, nos termos da lei;

Diante dessas incoerências, é pertinente o pensamento de Ronald Dworkin sobre o tema, uma vez que trata diretamente sobre a necessidade de coerência legal:

Temos dois princípios de integridade política: um princípio legislativo, que pede aos legisladores que tentem tornar o conjunto de leis moralmente coerente, e um princípio jurisdicional, que demanda que a lei, tanto quanto possível, seja vista como coerente nesse sentido. (DWORKIN, 1999, p. 213)

Percebe-se, portanto, a construção de, pelo menos, dois romances no Direito brasileiro: Um com garantias processuais mínimas, respeitando direitos constitucionais e outro com "flexibilização" de direitos, até mesmo da Constituição Federal de 1988. O caso Rafael Braga é exemplo claro dessa incoerência, tendo o negro, catador de latinhas, morador da favela de Vila Cruzeiro, sido condenado unicamente com base no depoimento de policiais, diretamente interessados na sustentação de suas versões para os fatos. Ao contrário do que se espera do recurso testemunhal, teoricamente idôneo e desinteressado.

Dworkin (1999, pp. 303-304) ao descrever a atuação de seu modelo de juiz ideal, reconhece no magistrado uma atuação política e moral, entretanto, não de forma descomprometida com a justiça e equidade. Pelo contrário, a coerência moral do direito como integridade só faz sentido na atuação hercúlea, se relacionada a esses filtros. 


\section{A GUERRA AS DROGAS E AS PRISÕES FUNDADAS EXCLUSIVAMENTE NA PALAVRA DO AGENTE PÚBLICO}

Onze anos, três meses, e multa no valor de 1687 reais $^{5}$, essa foi a pena imputada a Rafael Braga Vieira pelo pretenso porte com finalidade de tráfico de 60 gramas de Cannabis (maconha) e 9,3 gramas de cocaína. Esse não é um caso isolado. Por isso mesmo, o Brasil não é "o país da impunidade" como tanto vociferam jornais e programas policiais. Pelo menos não para o pobre, negro, morador de favelas. Para esses, o Estado prende muito e prende mal, tendo grande destaque a repreensão ao tráfico de drogas, grande inimigo coletivo das sociedades ocidentais, junto com o terrorismo, em sucessão ao comunismo. Dessa forma, criando um conveniente Estado de exceção permanente, onde garantias fundamentais são menos importantes que populismos penais.

Segundo dados INFOPEN, 66.313 pessoas estavam presas em 2014 por crimes relacionados a entorpecentes. Isso sem levar-se em consideração os diversos delitos que dele decorrem, como roubos, assaltos, latrocínios, lavagem de dinheiro, dentre outros. Ainda assim, o tráfico e o consumo mantêm-se constante da realidade brasileira bem como na mundial. Apesar disso, na contramão do mundo ocidental, o enfrentamento a essa situação no Brasil vem sendo insistentemente feito através do direito penal, e não por vias do que de fato é: um problema de saúde pública. Desse modo, preservando os interesses de políticos demagogos e narcotraficantes, em detrimento da integridade física e mental da população, especialmente dos usuários e moradores da periferia, sujeitos a toda sorte de truculências de ambos os lados.

A respeito da questão policial, pela natureza do caso em questão, torna-se necessário indicar o motivo pelo qual é tão frágil o uso do testemunho policial como prova em processos criminais. $\mathrm{O}$ agente repressor (policial) tem o um claro interesse em defender a legalidade dos seus atos. Desse modo, as acusações dirigidas ao réu, preso por ele, não são de forma alguma o que se pode chamar de "desinteressadas e idôneas". Tanto que, se provada a inocência do acusado, sua atuação passa a ser rodeada pelo espectro do abuso de autoridade. Nesse sentido, o professor de Direito da Universidade Federal do Rio de Janeiro - UFRJ, Antônio Carlos Melchior coloca:

Conceitualmente, as testemunhas (como os meios de prova em geral) servem para produzir conhecimento nos autos do processo, declarando o que sabem a respeito do fato imputado ou, no caso da defesa, sobre qualquer coisa eventualmente favorável ao réu. Ressalvados os vínculos que

\footnotetext{
5 Processo No 0008566-71.2016.8.19.0001
} 
lhe retiram o compromisso, as testemunhas devem ser "pessoas desinteressadas com o mérito do julgamento" e, portanto, não podem ter relação pessoal direta com o que se discute nos autos. (MELCHIOR, 2017)

No caso Braga, o imputado ainda acusava os agentes polícias de tê-lo incriminado, versão corroborada por uma moradora local, testemunha ocular do ocorrido ${ }^{6}$. Portanto, caso verdade fosse, os agentes polícias seriam obrigados a confessar, produzindo provas contra si mesmos, para dizer a verdade em juízo. Apesar disso, o juiz Ricardo Coronha Pinheiro, ignorando princípios como o in dubio pro reo (presunção de inocência) condenou de forma severa. O mais preocupante, todavia, é que esse é comportamento é corriqueiro no Judiciário brasileiro. No estado do Rio de Janeiro, inclusive cristalizado na súmula 70 do TJ-RJ, usada como fundamentação pelo juiz.

Nesse contexto, é pertinente atentar-se para os números divulgados pelo Núcleo de Estudos da Violência da Universidade de São Paulo - USP: policiais foram ouvidos em $76 \%$ dos inquéritos de São Paulo, sendo a única prova em estarrecedores $74 \%$ dos inquéritos por tráfico de drogas. Em concomitância com isso, dados da Fundação Getúlio Vargas mostram que a própria instituição Polícia encontra-se em grave descredito com a sociedade: "Cerca de um terço dos brasileiros afirmou confiar no Poder Judiciário, número ligeiramente abaixo à confiança nas emissoras de TV (33\%) e um pouco superior à confiança na polícia (25\%)" (CUNHA et al., 2016, p. 15). Ou seja, em nome da guerra as drogas, o Estado acusa (polícia), julga (juízes), e pune (presídios) tendo não mais somente o monopólio da força e da lei, mas agora, também dos fatos.

Assim, sob a neblina turva de algo que se assemelha formalmente a um processo legal adjetivo (porém não o sendo para boa parte do mundo jurídico), esfarela-se em um só golpe: o devido processo legal, a justiça e boa parte das garantias individuais do artigo $5^{\circ}$ da Constituição Federal do Brasil (1988), bem como o mérito das revoluções liberais, com seus séculos de evolução, nela refletido. Dinâmica macabra perfeitamente expressa pelas palavras do professor Roberto Lyra Filho (1982, p.5)

Diríamos até que, se o Direito é reduzido à pura legalidade, já representa a dominação ilegítima, por força desta mesma suposta identidade; e este "Direito" passa, então, das normas estatais, castrado, morto e embalsamado,

\footnotetext{
${ }^{6}$ Testemunha dispensada pelo juiz, alegando interesses extrafactuais na liberação do réu, por ser "vizinha há muitos anos".

${ }^{7}$ O professor Roberto Lyra Filho pertence a uma corrente teórica diferente da do autor aqui proposto: Ronald Dworkin. Portanto, com objetivo de manter uma clareza de ideias, sem perda de foco, sua teoria não será trabalhada nesse artigo.
} 
para o necrotério duma pseudociência, que os juristas conservadores, não à toa, chamam de "dogmática".

\title{
4. FALÊNCIA DO SISTEMA CARCERÁRIO, E DESRESPEITO Á DIGNIDADE HUMANA
}

654.372, esse é o número que atualmente representa o mundo a parte que é o sistema carcerário brasileiro. Esse amontoado de seres humanos encarcerados nos insalubres, perigosos e violentos presídios dispostos no território nacional. A superlotação é evidente, segundo o Anuário Brasileiro de Segurança Pública - 2016, o Brasil dispunha de 370.860 vagas para 584.361 detentos no ano de 2014. Ou seja, 1,6 preso por vaga, sendo ainda mais periclitante em estados federados como o Amazonas, com impressionantes 3,8 presos ocupando o espaço destinado a somente 1. Por isso, infelizmente não surpreendente, as recentes tragédias nesses locais protagonizados, como rebeliões e chacinas. Essa realidade é explicada não só pela superlotação, mas também pela total falta de estrutura e higiene das unidades prisionais.

\begin{abstract}
Os fatores materiais indicam que as instituições penitenciárias podem ocasionar efeitos danosos na saúde dos condenados, devido as suas condições materiais precárias e alimentação deficiente, sendo um local inadequado para a permanência humana que favorece no desenvolvimento e propagação de doenças entre os presos. São inúmeros os fatores materiais que colaboram com a propagação de doenças dentro das instituições carcerárias, dentre eles, a falta de higiene nas celas ocasionada pela insalubridade merece destaque. (PIVA; RAMIDOFF, 2015, p.76).
\end{abstract}

Desse modo, deturpa-se o objetivo maior, da instituição da pena privativa de liberdade: recuperar para ressocializar. É extremamente improvável que em um aglomerado humano dessa natureza, sem assistência mínima, com direitos violados, é na presença de toda sorte de influências, o indivíduo apenado restaure-se moralmente para a vida em sociedade, prova disso são as altas taxas de reincidência brasileiras.

Nesse panorama, parece ainda mais preocupante que a cultura jurídico-política nacional ainda seja pautada em solução de problemas culturais ou de saúde pública (como as drogas atualmente ilícitas) pela via da repressão penal, obviamente falha. Parece haver uma separação no imaginário popular, quase criadora de subespécies, para alocar detentos e criminosos em um grupo não pertencente a aquela comunidade. Esse subgrupo, em continuidade ao processo de marginalização (uma vez que, normalmente já o é pela via socioeconômica pregressa), vê a 
própria dignidade humana torna-se mitigável. Fato preocupante, tanto na perspectiva dos Direitos Humanos quanto como termômetro para a solidariedade intracomunitária.

Por sua vez, Dworkin já alertava para o valor intrínseco de cada vida, sendo sua dignidade como pessoa humana merecedora de todo esforço para a sua preservação. Nesse sentido Anna Carolina Venturini (2011, p. 91) sustenta:

\begin{abstract}
Dworkin considera que toda vida humana tem um valor quanto ̀̀ potencialidade, de modo que, iniciada uma vida, torna-se importante como ela se desenvolve. Assim, o sucesso ou o fracasso de uma vida humana não é importante apenas para a própria pessoa, mas é importante em si mesmos, é algo que todos nós temos uma razão para desejar ou lamentar.
\end{abstract}

Ainda sobre a dignidade, Dworkin a subdivide em duas dimensões: uma de valor intrínseco, ou seja, reconhecer importância na próxima existência, e o da responsabilidade pessoal, que, bem a tradição liberal, reconhece no indivíduo responsabilidade pelo próprio sucesso.

Com a aculturação penitenciária, a falta de acesso a comida em quantidade e qualidade mínima, saneamento básico, e violência física, psicológica e sexual, seria milagrosa a perseverança do reconhecimento de um valor intrínseco a si pelos apenados. Revelando um elevado grau de crueldade por uma perspectiva dworkiana, que, em linguagem mais popular, seria melhor visualizado, como a supressão do amor próprio. Nas palavras do autor:

(...) esse princípio não exige que as pessoas nunca sejam colocadas em desvantagem com o objetivo de oferecer vantagens a outras, mas sim que nunca sejam tratadas de maneira que se negue a evidente importância de suas próprias vidas (DWORKIN, apud BARBOSA; COSTA, 2016 p. 309).

Destarte, comprova-se a violência que o Estado implica aos seus detentos, legalmente sob sua tutela, bem como o retumbante fracasso no seu papel ressocializador.

\title{
CONCLUSÃO
}

Ronald Dworkin estabelece uma teoria do direito baseada em princípios, com destaque para a integridade, justiça, equidade e devido processo legal. Sob esse marco teórico torna-se mais fácil perceber as arbitrariedades do Estado brasileiro. Rafael Braga é símbolo de um Direito torto, 
escrito por autores bem definidos, com traços característicos, e não pela comunidade personificada pretendida.

Aqui se estabelece a construção de dois romances em cadeia, por juízes teoricamente sujeitos ao mesmo sistema legal, mas que o aplicam de forma diferente, e muitas vezes arbitraria, sob a lógica entranhada na consciência colonial do Brasil. Na contramão do mundo, aposta-se no punitivismo e no encarceramento para combater os reflexos de uma sociedade desigual em tudo. Dessa forma, eternamente recriminando os setores mais sofridos da sociedade como se fossem eles a causa do caos.

Por isso mesmo, no imaginário político popular, indignos de investimento, de conforto (ainda que mínimo), de higiene, de direitos. Tempos sombrios anunciaram-se, e agora estão a porta, forçando passagem pelos Direitos Humanos e garantias constitucionais em nome da preservação de um status quo, que há muito deveria estar sepultado.

A dignidade é, cada vez mais abertamente, tratada como privilégio dos "bons". Renegando aqueles que já foram renegados pela vida ao limbo da incerteza e do sofrimento. Pois se dignidade não é mais coisa humana, errar também não o é. Urge num Brasil contemporâneo, mas que nunca foi nem ao menos moderno, muito mais do que mais gaiolas humanas, para amontoar mais e mais o que os "bons" não querem ver. Lamentavelmente, é inadiável a reforma de mentes, mais importante, até que, as das selas imundas dos presídios nacionais (também mais que urgentes).

O fetichismo penal é tão popular quanto é ineficiente, ceifando a vida dos que matam e morrem pela e para a aplicação da lei imposta de cima para baixo, por um Estado alheio a realidade e aos números. Pelo menos, aos que refletem a agonia e muitas vezes a morte, dos que nada mais aparentam ser nos imaginários incompreensíveis dos encastelados políticos nacionais, do que um voto em época de eleição, clamando, inflamados pelos sensacionalistas programas policiais de televisão e afins, por penas cada vez mais duras, mas que não resolveram e nem resolverão distúrbios culturais como o machismo, o racismo, é a LGBTfobia, ou sociais como a falta de acesso à educação, alimentação e vida digna para significativa parte da população. Esses sim, minas incessantes das revoltas e dos revoltados que tanto assustam o Brasil, bem como seus filhos medianos.

Dignidade não é privilégio, errar também não, talvez um não o seja porque o outro também não o é. Se não somos iguais perante a lei, diante do sofrimento não podemos deixar de ser. Segurança pública é essencial, mas o homem é fim, jamais meio. Seu sofrimento por sua vez, muito menos. Como disse Emmanuel Kant em seu imperativo categórico: " Age de tal forma que 
uses a humanidade, tanto na tua pessoa, como na pessoa de qualquer outro, sempre e ao mesmo tempo como fim e nunca simplesmente como meio."

O auto-reconhecimento se faz necessário, não existem "eles" contra "nós". Após tantas guerras e barbáries, seja na Alemanha do século 20, ou na comunidade de Vila Cruzeiro, passa da hora de reconhecermos que é nossa humanidade que nos protege. Todavia, nesse campo de batalha, não há muros de condomínio, pois só há garantias e segurança jurídica, na equidade e na isonomia, já que, a justiça (abstrata) só defende a coerência, jamais, o egoísmo ou a hipocrisia.

\section{REFERÊNCIAS:}

BRASIL. Constituição Federal de 1988. Promulgada em 5 de outubro de 1988. Disponível em < http://www.planalto.gov.br/ccivil_03/constituicao/constituicao.htm/> Acesso em: 28 de maio de 2017.

BRASIL. Tribunal de Justiça. Sentença n. 0008566-71.2016.8.19.0001. Juiz: Ricardo Coronha Pinheiro. Disponível em:

<http://www1.tjri.jus.br/gedcacheweb/default.aspx?GEDID=00040DF0FF64CDE7A6B8EAF E5F0FDFEB80C5E6C50621360E/>. Acesso em: 28 maio de 2017.

BARBOSA, Evandro; COSTA, Thaís Cristina Alves. A CONCEPÇÃO DE DIGNIDADE HUMANA EM RONALD DWORKIN: UM PROBLEMA DE ÉTICA PRÁTICA. Griot: Revista de Filosofia, Amargosa, v.13, n.1, p. 306-316, Jun. 2016.

CONCELHO NACIONAL DE JUSTIÇA. Reunião especial de jurisdição. 2017. Disponível em:

< http://www.cnj.jus.br/files/conteudo/arquivo/2017/02/b5718a7e7d6f2edee274f93861747304 .$/>$

Cf. FONSECA, Anderson Lobo da. A Força da Palavra Repressiva. In: Le Monde

Diplomatique Brasil, ano 8, n. 93, Abril. 2015, p. 32-33. Disponível em <

http://diplomatique.org.br/a-forca-da-palavra-repressiva/> Acesso em: 28 maio de 2017.

CUNHA, Luciana Gross et al. Relatório ICJBrasil-1º semestre/2016. Escola de Direito de São Paulo da Fundação Getúlio Vargas (DIREITO GV), 2016.

DEPARTAMENTO PENITENCIÁRIO NACIONAL, Ministério da Justiça. Levantamento Nacional de Informações Penitenciárias INFOPEN DEZEMBRO DE 2014. Disponível em: $<$ http://www.justica.gov.br/seus-direitos/politica- 
penal/documentos/infopen_dez14.pdf\&ved=0ahUKEwiF9ruarKPUAhXIeCYKHdSeAWwQFg gmMAE\&usg=AFQjCNEmtu24yIRe-

Jno1HZR_1XUJo3IUQ\&sig2=ssJ2oA6kirnR7Vmt5FB6DA/> Acesso em: 25 de maio de 2017.

DWORKINN, Ronald. Império do Direito. (Trad. de Jefferson Ruiz Camargo). $1^{\circ}$ ed.São Paulo: Martins Fonte, 1999.

FERRI, Caroline Feliz Sarraf. Teoria da integridade: Uma abordagem da sistematização de Ronald Dworkin. In: Âmbito Jurídico, Rio Grande, XVI, n. 111, abr. 2013. Disponível em: <http://www.ambitojuridico.com.br/site/?n_link=revista_artigos_leitura\&artigo_id=13123/ >. Acesso em 28 maio 2017.

Fórum Brasileiro de Segurança Pública. Anuário brasileiro de segurança pública 2016 [Internet]. São Paulo: Fórum Brasileiro de Segurança Pública; 2016. Disponível em <http://www.forumseguranca.org.br/wpcontent/uploads/2017/01/AnuarioSite27-01-2017RETIFICADO.pdf/> Acesso em 28 maio 2017.

FUNDAÇÃO GETULIO VARGAS. Pesquisa do ICJBrasil avalia confiança nas instituições do Estado. Disponível em< http:// fgvnoticias.fgv.br/pt-br/noticia/pesquisa-doicjbrasil-avalia-confianca-nas-instituicoes-do-estado\#/> Acesso em: 28 maio 2017.

JESUS, Maria Gorete Marques de et al. Prisão Provisória e Lei de Drogas - Um estudo sobre os flagrantes de tráfico de drogas na cidade de São Paulo. São Paulo: NEV- USP, 2011. Disponível em: < http://redejusticacriminal.org/pt/publication/prisao-provisoria-e-leide-drogas-um-estudo-sobre-os-flagrantes-de-trafico-de-drogas-na-cidade-de-sao-paulo// > . Acesso em: 22 de maio de 2017.

LYRA FILHO, Roberto. O que é direito. São Paulo: Editora Brasiliense, 1982.

MELCHIOR, Antônio Pedro. Condenar Rafael Braga apenas com base na palavra policial viola o processo penal brasileiro . Disponível em:< http://justificando.cartacapital.com.br/2017/04/22/condenar-rafael-braga-apenas-com-base-napalavra-policial-viola-o-processo-penal-brasileiro//>. Acesso em 28 maio 2017.

PIVA, Mariana; RAMIDOFF, Mário Luiz. Sistema penitenciário brasileiro: (Dis)Função (Des)Socializadora. Panóptica, vol. 10, n. 2, 2015 (jul./dez.), pp. 73-92. 
VENTURINI, Anna Carolina. A dignidade e os direitos humanos: a concepção filosófica de Ronald Dworkin. Revista Acadêmica Direitos Fundamentais, Osasco, Ano 5, n.5, p 89 - 97 , 2011. 